\title{
Application of Water Element in Modern Landscape Design
}

\author{
Ling Zhang \\ Eastern International Art College \\ Zhengzhou University of Light Industry \\ Zhengzhou, China 451450
}

\begin{abstract}
The water landscape design is one of the difficulties in landscape art design, but also the visual focus on environment. In the classical gardens of the east and west, the application of water resource is everywhere, whose existence beautifies landscape, injects vigor into environment and brings vitality. With the arrival of the Industrial Revolution age, the existing quality of human declines continuously. People long for nature more and more, and water exactly satisfies people's material and spiritual demand of get close to nature.
\end{abstract}

Keywords - water; landscape design; the industrial revolution; demand

\section{INTRODUCTION}

Water is an essential substance which creatures depend on for existence. It is the link between human and nature with strong plasticity. It has become an indispensable link in landscape design, which plays an irreplaceable role. Water makes natural environment generate anima, makes people more willing to get close to it, and makes it more harmonious between environment and human. The water influences and enriches human's realm of spirit, the highlight of which is landscape effect, which is a spiritual resource stimulating human's sense organs and making people peaceful. As one of the landscape elements, the water is always beautifying environment and injecting fresh blood into environment, no matter in classical Chinese gardens or classical western gardens. The water has features of being flexible and utilizable, which not only ensures daily life demand of living and production water consumption, but also fully considers human's behavior features via design, creating landscape to view water and get close to water to meet human's basic physical and mental demands. Over the years, with the development of society and improvement of people's life, people raise higher and higher claims to natural environment, such as configuration of plant and design of water landscape. Thereinto, as one of important ways to beautify environment in landscape design, water element is more and more applied to landscape design.

\section{DESIGN Form OF WATER LANDSCAPE}

\section{A. It Can Be Divided into Natural Form and Regular Form according to Water Form}

In gardens, no matter the water appears as main scenery or subordinate scenery, it has two forms of application in general: natural water and regular water. In ancient Greece, influenced by development of math and geometry and aesthetics viewpoint of philosophers, people thought beauty was represented via mathematical ratio, which was entirety with rule and order conforming to coordinating ratio, and only to stress the balanced stable regular style can beauty be generated. Thus at that time, landscape layout in this regular style came into being under such aesthetic ideology. Natural water imitates natural form but is higher than nature, which combines artificial beauty with natural beauty and achieves "wonderful workmanship as nature", namely stressing natural beauty, and it was influenced by Taoism and geographical conditions at that time. Natural water is mainly design conducted by using existing terrain or civil structure, which can naturally exist or be built artificially, and its forms are mostly irregular and exist in curve forms, and such water is often applied in our traditional gardens.

Regular water is a water-storage volume built artificially, whose edge is smooth and modeling is mostly geometric shape, applying to controllable artificial environment.

Natural water: generated from artificial imitation of natural water landscape, natural or imitated river, lake or spring, changing with terrain in landscape.

Regular water: geometrical water surface built artificially, such as canal, ditch, pond and well.

The water form and size design shall fully consider human's behavior feature, and refer to factors in many aspect such as human's own size and psychological enduring capacity.

\section{B. It Can Be Divided into Dynamic Form and Static Form according to Condition of Water Flow}

The so-called static water is in relative terms with dynamic water, static water landscape means it has no sound itself and is very peaceful. These are all the visual and auditory sense of human. In fact, most static water is flowing, 
but it flows slowly. If the water is completely static, it will be dirty, making it difficult to become high-quality water landscape of gardens. Dynamic water landscape is divided into flowing water, falling water and spraying water, and these forms can also develop some different forms, especially with the development of technology, the falling forms are changing greatly. Different atmosphere can be created in different situations, bringing people different feelings. Like the music fountain square, such environment brings people peaceful and relaxing visual enjoyment, suitable for people's leisure space.

\section{CLASSIFICATION OF WATER LANDSCAPE DESIGN}

\section{A. Pond}

The pond is one of the most common water landscapes, which always locates in the core area of traditional gardens and forms the central landscape of the whole garden. The forms of pond are divided into regular ones and irregular ones. The regular ones often appear in geometric shape, which are often used in western gardens. There is a clear middle axis in the garden, and there is pond and fountain on the middle axis, the form of water landscape is abundant, generally square, round, regular symmetrical planes with lat of fun. There are big and small ponds, and small ponds can provide striking key points landscape, often serving as visual center. Mountains can be built over the pond to form pond mountains, which can be individually set or combined with other facilities, always in special shape and serving as visual focus of the space. Large-scale water surface can form controllable artificial lake landscape, often appearing in living environment. The forms of pond shore are various, straight or curving, highlighting composition and formal beauty via artificial shape, matched with footpath, corridor and plant, setting off the leisurely ecological atmosphere, so beautiful.

\section{B. Waterfall}

Waterfall in landscape design often refers to artificial waterfall imitating nature, generally landscape formed of lot of water falling down from high combined with artificial rocks. It is mostly represented with modern design methods and shows strong artificiality. The viewing effect of waterfall is more abundant than flowing water, and it can show the feature of water source in landscape most. It can show the momentum and innervation of water, making viewers relaxed and happy, and it often serves as visual focus in outdoor environment layout. The waterfall often consists of five parts of water source, falling open, waterfall body, waterfall-pood and outfall, and its water flow features depend on flow quantity, flow rate, altitude difference and condition of edge of outfall. When processing design, carefully research the edge of falling water, and different edge forms represent different water falling effects.

\section{BASIC PRINCIPLE OF DESIGN OF WATER LANDSCAPE}

\section{A. Reflect Nature, Pay Attention to Ecology, Meet Functional Requirement}

In landscape design, first of all it shall clarify the basic function of water, and combine it with other functional demands to design space environment, use water effectively, reduce water consumption. The basic function of water is to bring people feeling of beauty, become the visual focus, offer site for people to enjoy, dabble, amuse and exercise, so firstly design shall satisfy art aesthetic feeling. Take as many measures as possible in design, use different water types such as water playing pond, fountain and stream, enrich the functions of landscape space.

The water has not only aesthetic value, but also function to adjust microclimate, collect dust, reduce noise and clean air, and adjust humidity and temperature of air. Especially the small droplet particles sprayed by fountain have rich negative oxygen ion, and people feel relaxed and the air is fresh in it. In landscape environment of modern communities, especially in the north there is much floating dust, and the humidity of air is insufficient, and large area of water design can effectively adjust humidity and temperature of the environment, improve ecological environment of the mircoclimate in community and stabilize the temperature of community environment.

\section{B. Overall Requirement of the Environment}

In landscape design of environment, design of water landscape shall fully reflect art function and viewing feature of water, and coordinate with the whole landscape. If the water serves as the core of building space, it can form a focus or center in certain space. The water often exists as a scenic spot in the space for its special vitality. Thus in design, if the design of water landscape wants to reach expected effect of landscape, it shall firstly research the environment elements and geographical conditions, and decide the type of water, make the water form beautiful, balanced and wellproportioned in graphic design, make it beneficial to landscaping and maintenance of water, and reflect the variability of water. Adjust measures to local conditions, do according to abilities, form its own features but not all in the same key, realize coordination with environment. Form harmonious composition of picture, enrich and harmonize spatial level. Design and approve future operation, maintenance, cleaning, purification and input cost to avoid future trouble or overreaching.

\section{Scale of Water Design Shall Be Suitable, Harmonious and Uniform}

A water landscape successfully designed shall be in pleasant scale, which has to reflect respect to people, fully consider human's behavior features, combine with knowledge related to human engineering, refer to basic scale, static and dynamic spatial scale and psychological effect of human. The water is not independent in landscape design, and it has to draw support from other carriers to better satisfy people's demand of landscape design. So the form and scale of water shall be combined with elements such as hillstone, 
bridge, aquatic plant, sculpture and light, coordinate with them and form a landscape space. Attract people to gather around it and make it the core space of human's vision and activities.

\section{The Safety of Design of Water Landscape}

The water is not static or invariable, and on the contrary, its destructive power can be striking. Thus in design of water landscape, firstly figure out the function of water landscape and consider its safety. Generally the water appears in the form of viewing, dabbling and offering living environment for aquatic plants and animals. In design, fully consider the close relation between human and water, and only suitable water depth can form harmonious living environment. Common dabbling water landscape often attracts people's participation. If such water is too deep, it might cause to drowning of children. If the water is too shallow, it might reduce the purifying ability of water, worsen the water quality and damage ecological environment. Thus in the design of water landscape, the above conditions shall be fully considered, and corresponding safeguard procedures toward special water landscape shall be set. Measures like setting guard bar, ground antislipping treatment and widening the gradient of water bank can protect people's safe and ensure the purification of water quality.

\section{CONCLUSION}

Today, economy is developing fast, and people's living standard improves day by day, making people's requirement to water environment higher and higher. We urgently hope to improve present situation, improve living environment and acquire mental and spiritual emotion via creation of water landscape. Thus, it's necessary for us to review and reappraise the relation between human and nature, and understand that in certain conditions, as a natural object, the water can not only satisfy the demand of aesthetic feeling, but more importantly, it can fundamentally improve people's ecological environment, maintain ecological balance and keep sustainable development. We shall research, analyze and apply water resource, this special topic to develop and protect it more scientifically.

\section{REFERENCES}

[1] Zhang Junhua. Landscape Design in Residence Zone. III. First edition [M]. Beijing:China Architecture \& Building Press, 2001:06

[2] [UK]Cliff Moughtin. Street and Square. Translated by Zhang Yonggang, Lu Weidong. Beijing: Beijing: China Architecture \& Building Press, 2004

[3] Ding Yuan. Water-front landscape design [M]. Beijing: Higher Education Press.2010.52-68

[4] Ding Yuan. Introduction of Landscape Design [M]. Beijing: Higher Education Press.2008.89-94

[5] Lin Baogang, Lv Xiaohui, He Quan: Environmental Landscape Design[M]. Wuhan:East China University of Science and Technology Press.2007.44-47

[6] Du Rujian, Li Enshan, Liu Guanping. Design of Garden Construction [M].China Architecture \& Building Press.1986.136
[7] Gong Ming . Simple Analysis on the Application of Water Landscape in Living Environment[J]. Newspaper of Hubei Institute Of Fine Acts, 2002 (3) 